\title{
Cryopreservation of Carp Spermatozoa
}

\author{
T. Francis ${ }^{1 *}$, C. Archana Devi ${ }^{2}$ and M. Selvamagheswaran ${ }^{3}$ \\ 1,2,3 Department of Fisheries Biology and Resource Management, Fisheries College \& Research Institute, \\ Thoothukudi -628008, Tamil Nadu, India; t_franciz2000@yahoo.com, archanacmcs@yahoo.com, \\ sunaocean@yahoo.com
}

\begin{abstract}
A successful cryopreservation method would offer many advantages to an aquaculturist. Cryopreservation can provide a year round supply of seeds from desired species regardless of the spawning season and allow hybridization, greater ease in carrying out selective breeding and stock improvement. Studies were conducted on cryopreservation of spermatozoa from Indian major carps. Effect of different concentration of glycerol and equilibration periods on the post thaw motility of spermatozoa from Catla, Rohu and Mrigal were observed. The maximum motility ( $80-85 \%)$ was observed with the equilibration period of $20-40$ minutes with the concentration of $10-15 \%$ of glycerol. Rohu showed the same trend with the maximum motility of $78-87 \%$. In Mrigal maximum motility (85-88\%) was observed with the equilibration time of (20-40 minutes) with the concentration of glycerol in between (10-15\%). Like glycerol, the same type of experiment was conducted with Dimethyl sulphoxide (DMSO). Post thaw motility of cryopreserved spermatozoa in DMSO showed the same way as glycerol. Apart from the above, percentage of motility of spermatozoa was observed with respect to different thawing temperatures. Maximum motility was observed at the thawing temperature of $40^{\circ} \mathrm{C}$ in catla (85\%), Rohu (80.00\%) and Mrigal (83\%). Interesting results were obtained from the fertilization studies of cryopreserved spermatozoa of Catla with the eggs from the matured Catla breeders. Fertilization rate of $75-80 \%$ and the hatching rate of $60 \%$ was observed from the above study. From the above results, it could be possible to use cryopreserved spermatozoa for commercial production of fish seeds in fish hatcheries.
\end{abstract}

Keywords: Cryopreservation, Catla, Rohu, Mirgal, DMSO, Fertilization Rate.

\section{Introduction}

In recent years, the increasing demand for the proteinaceous food has driven the aquaculturist to maximise the fish production. This in turn has increased the demand for fish seeds. As a result, the need to ensure a dependable source of quality seeds has been greatly felt. Though the demand for fish seeds is met with hyphophysaton technique to a larger extent, the asynchronisation in the gonadal maturation of the male and female breeder pose problem in successful breeding of some cultivable species. To solve the shortage in seed production arising out of asynchronisation of gonadal maturation, the preservation of gametes promises to be very useful technique by facilitating artificial breeding.
A successful cryopreservation method would offer many advantages to an aquaculturist. cryopreservation can provide a year round supply of seeds from desired species regardless of the spawning season and can allow hybridization, greater case in carrying out selective breeding and stock improvement. Gametes from desired fish can be transported from one place to another place easily and also the number of males maintained can be reduced.

In 1949, Polge et al. [29] introduced glycerol as a protective agent against the deleterious effects of ice crystals formed during cryopreservation. Blaxter [3] was the first to use glycerol as a cryoprotectant to successfully cryopreserve the sperm of Atlantic herring in a frozen condition. Now a day's liquid nitrogen is widely used for cryopreservation [17].

* Corresponding author:

Francis (t_franciz2000@yahoo.com) 
The viability of frozen spermatozoa can be maintained for longer periods, only when careful attention is given to the collection of milt, dilution with extenders, equilibration time for the penetration of cryoprotectant into sperm head, freezing and thawing methods. In the cryopreservation technology the viability of cryopreserved sperm could be assessed by the intensity of their motility and their capacity to fertilize the ova. Motility is still considered the principal assay for the evaluation of fish sperm viability before and after freezing. Most of the studies on cryopreservation have been restricted to the cold water species, especially salmonids [1]. There have been a few published reports on the successful cryopreservation of sperm of cultured warm water species [15]. Among them, carps have been the subject of most of the cryogenic studies [18] because of their economical importance in aquaculture and availability of adequate information on their biology and on reproductive physiology, besides their ready availability for research purposes in government and private farms.

However, studies conducted on the cryopreservation of carp sperm have shown a very high inconsistency in the viability of post thawed sperm which make the methods unreliable. Therefore it is necessary to develop a simple and reliable procedure for the cryopreservation of carp sperm. Experiments were carriedout to determine various factors influenzing the viability of carp sperm during freezing and thawing. Though different extenders and cryoprotectant are available to cryopreserve carp sperm, studies on post thaw motility at different concentration of croprotectant with different equilibration period is lacking. Hence, experiments were carriedout to study the post thaw motility of spermatozoa from Catla, Rohu and Mrigal with different concentration of glycerol with different equilibration time. After cryopreservation, the motility and fertilizing capacity of cryopreserved sperm were studied.

\section{Materials and Methods}

The milt was collected from the fishes, after 12 hours of hormonal administration. Prior to the collection of milt, the abdomen of the fish was wiped with absorbent paper to remove moisture and water, if any, so as to avoid unexpected activation of the spermatozoa. The vials containing milt samples were kept on the crushed ice and transported from the farm site to the laboratory. Milt collected from the fishes was kept separately for estimating the quality of milt. A drop of milt was placed on a class slide and was activated by adding a drop of water. The percentage of motility of the spermatozoa was evaluated microscopically following the guidelines suggested by Terner [38]. Those milt samples showing more than $90 \%$ motility alone were selected for further processing. The diluents (extender and cryoprotectant) and glassware were kept together with the milt, to keep cool and also to avoid temperature shock.

Dimethyl sulphoxide (DMSO) and glycerol were used as cryoprotectants for this investigation. Various concentrations of DMSO and glycerol at 5\%, 10\%, 15\%, 20\%, 30\% and 50\% level for Catla, Rohu, Mrigal were mixed with their respective best extender (Modified Cortland medium). The milt was diluted to 1:10 ratio with the diluents (extender and cryoprotectant) and equilibrated for 20 minutes and then frozen in liquid nitrogen vapour at a freezing rate of $-154{ }^{\circ} \mathrm{C} / \mathrm{min}$. The frozen samples were stored in liquid nitrogen $\left(-196{ }^{\circ} \mathrm{C}\right)$. The performance of different concentrations of cryoprotectants was assessed after 20 days of preservation in liquid nitrogen.

The milt of common carp, mrigal and rohu diluted with respective diluents (Cortland medium + glycerol/ DMSO) was drawn into $0.5 \mathrm{ml}$ straws. The filled straws were sealed with the sealing powder, polyvinyl alcohol. Straws and PVA powder of different colors were used for the ready identification of samples. The sealed ends were dipped in cold water $\left(5^{\circ} \mathrm{C}\right)$ for proper sealing. Filling and sealing of straws were carried out in the cold handling chamber.

The spermatozoa of Catla, Rohu, Mrigal suspended in the diluents at a dilution ratio of 1:10 (10\% DMSO and $10 \%$ glycerol as individual cryoprotectants) were equilibrated at $5^{\circ} \mathrm{C}$ for varied periods of $5,10,20,40,60,120$ and 180 minutes. The straws with diluted milt were frozen, after exposing them to an equilibration time of 20 minutes. The equilibrated straws were arranged on a rack in an insulation box containing adequate volume of liquid nitrogen. The straws were frozen in liquid nitrogen vapour at different freezing rates. After 10 minutes of freezing, the straws were immersed in liquid nitrogen kept in a cryo can for a preservation period of 30 days.

The frozen sperm samples of Catla, Rohu and Mrigal were thawed in water bath at varying temperature levels, viz., $30^{\circ} \mathrm{C}, 40^{\circ} \mathrm{C}, 50^{\circ} \mathrm{C}, 60^{\circ} \mathrm{Cand} 70^{\circ} \mathrm{C}$ in order to evaluate the viability of frozen spermatozoa at different thawing temperature. The stored samples were tested for their fertilizing capacity. About 200 to 275 ripe ova were stripped directly into petridishes and were fertilized with stored spermatozoa from one or two straws as required for individual experiments. They were used immediately after stripping. The thawed milt was immediately mixed well 
with ova by using a feather. The water was added after 1 minute of mixing. The viability of sperm was estimated by the percentage recovery of fertilized eggs with embryo. The results obtained were subjected to the analysis of variance (ANOVA) to test their significance [31].

\section{Results and Discussion}

Various factors which influence the post thaw motility of the spermatozoa of catla, Rohu and Mrigal during cryopreservation were studied. Different equilibration time, which allow the good penetration of cryoprotectant into the sperm cells and the best thawing temperature, at which, frozen spermatozoa were brought back to normal condition were also studied. In addition to the viability studies through the post- thaw motility of spermatozoa, the fertilization rate obtained with cryopreserved spermatozoa for the three carps Catla, Rohu, Mrigal were also examined

Effect of different concentration of glycerol and equilibration periods on the post thaw motility (\%) of the spermatozoa of Catla are given in Table 1. Among the different equilibration time and different percentage of glycerol, maximum motility ( 80 to $88 \%$ ) was obtained in catla with the equilibration period of 20 to 40 minutes. Among the different concentration of glycerol tried in Catla, the higher percentage of motility (72 to 88\%) was observed in 10-15\% of glycerol with respect to different equilibration periods and minimum percentage of motility was observed in 5 and 50 $\%$ glycerol with respect to different equilibration periods.

Effect of different concentration of glycerol and equilibration periods on the post thaw motility (\%) of the spermatozoa of Rohu and Mrigal are given in Table 2 and 3. Rohu and Mrigal showed the same trend as that of Catla.

Table 1. Effect of different concentration of glycerol and equilibration periods on the post thaw motility (\%) of the spermatozoa of Catla

\begin{tabular}{lccccccc}
\hline Extender & $\begin{array}{c}\text { Equilibration } \\
\text { time }\end{array}$ & \multicolumn{1}{c}{ Concentration of glycerol (\%) } \\
& & 5 & 10 & 15 & 20 & 30 & 50 \\
Modified & 5 & 64 & 82 & 81 & 72 & 70 & 65 \\
Cortland & 10 & 65 & 82 & 78 & 74 & 72 & 64 \\
Medium & 20 & 69 & 88 & 80 & 75 & 75 & 68 \\
& 40 & 70 & 85 & 78 & 75 & 74 & 64 \\
& 60 & 64 & 80 & 78 & 74 & 68 & 62 \\
& 120 & 64 & 78 & 72 & 75 & 70 & 60 \\
& 180 & 60 & 75 & 74 & 74 & 65 & 62 \\
\hline
\end{tabular}

Table 2. Effect of different concentration of glycerol and equilibration periods on the post thaw motility (\%) of the spermatozoa of Rohu

\begin{tabular}{|c|c|c|c|c|c|c|c|}
\hline \multirow[t]{2}{*}{ Extender } & \multirow{2}{*}{$\begin{array}{c}\text { Equilibration } \\
\text { time }\end{array}$} & \multicolumn{6}{|c|}{ Concentration of glycerol (\%) } \\
\hline & & 5 & 10 & 15 & 20 & 30 & 50 \\
\hline Modified & 5 & 66.25 & 85.25 & 81.75 & 79.00 & 74.50 & 69.25 \\
\hline Cortland & 10 & 64.75 & 83.75 & 79.50 & 75.75 & 72.25 & 66.25 \\
\hline \multirow[t]{5}{*}{ Medium } & 20 & 65.50 & 87.00 & 82.50 & 78.75 & 73.00 & 71.00 \\
\hline & 40 & 62.00 & 84.00 & 78.00 & 60.25 & 74.00 & 70.50 \\
\hline & 60 & 64.50 & 86.50 & 80.00 & 76.75 & 73.10 & 62.00 \\
\hline & 120 & 63.25 & 83.75 & 79.50 & 79.25 & 73.25 & 64.00 \\
\hline & 180 & 65.00 & 85.50 & 82.00 & 77.50 & 71.25 & 60.25 \\
\hline
\end{tabular}

Table 3. Effect of different concentration of glycerol and equilibration periods on the post thaw motility (\%) of the spermatozoa of Mrigal

\begin{tabular}{lccccccc}
\hline Extender & $\begin{array}{c}\text { Equilibration } \\
\text { time }\end{array}$ & \multicolumn{1}{c}{ Concentration of glycerol (\%) } \\
Modified & 5 & 5 & 10 & 15 & 20 & 30 & 50 \\
Cortland & 10 & 65 & 85 & 81 & 70 & 70 & 65 \\
Medium & 20 & 78 & 88 & 85 & 75 & 75 & 70 \\
& 40 & 80 & 86 & 85 & 78 & 75 & 72 \\
& 60 & 63 & 86 & 85 & 75 & 68 & 62 \\
& 120 & 65 & 84 & 80 & 70 & 65 & 64 \\
& 180 & 60 & 80 & 84 & 70 & 65 & 65 \\
\hline
\end{tabular}

Rohu showed the same trend with the maximum motility of ( 85 to $88 \%$ ) was observed with the equilibration period of 20 to 40 minutes. In the case of Rohu minimum percentage of motility (62 to $66 \%$ ) was observed in $5 \%$ of glycerol. In the case of Mrigal, the minimum percentage of motility (64 to $70 \%$ ) was observed in $50 \%$ of glycerol.

Effect of different concentration of DMSO and equilibration periods on the post thaw motility (\%) of the spermatozoa of Mrigal is given in Table 4. DMSO showed the same trend, as that of, glycerol in post thaw motility of spermatozoa. Among the different concentrations of DMSO tried in Catla, the higher percentage of motility ( 88 to $90 \%$ ) was observed in $10 \%$ of DMSO with respect to different equilibration periods and minimum percentage of motility was observed in $50 \%$ DMSO with respect to different equilibration periods.

Effect of different thawing temperature on the motility (\%) of spermatozoa of Catla, Rohu and Mrigal were given in 
Table 4. Effect of different concentration of DMSO and equilibration periods on the post thaw motility (\%) of the spermatozoa of Catla

\begin{tabular}{lccccccc}
\hline Extender & $\begin{array}{c}\text { Equilibration } \\
\text { time }\end{array}$ & \multicolumn{1}{c}{ Concentration of glycerol (\%) } \\
& & 5 & 10 & 15 & 20 & 30 & 50 \\
Modified & 5 & 75 & 85 & 85 & 75 & 72 & 65 \\
Cortland & 10 & 80 & 90 & 83 & 75 & 75 & 68 \\
Medium & 20 & 78 & 88 & 85 & 80 & 80 & 75 \\
& 40 & 80 & 90 & 82 & 80 & 82 & 75 \\
& 60 & 70 & 85 & 82 & 70 & 65 & 65 \\
& 120 & 75 & 85 & 81 & 70 & 70 & 65 \\
& 180 & 70 & 80 & 82 & 65 & 65 & 63 \\
\hline
\end{tabular}

Table 5. Effect of different thawing temperature on the motility (\%) of spermatozoa of Catla, Rohu and Mrigal

\begin{tabular}{lccc}
\multirow{2}{*}{$\begin{array}{l}\text { Thawing } \\
\text { temperature }\left({ }^{\circ} \mathrm{C}\right)\end{array}$} & \multicolumn{3}{c}{ Motility (\%) } \\
\cline { 2 - 4 } & Catla catla & C. mrigala & L. rohita \\
\hline 25 & 56.25 & 54.25 & 65.00 \\
30 & 79.25 & 80.00 & 76.50 \\
40 & 85.50 & 83.00 & 80.00 \\
50 & 73.00 & 71.00 & 69.00 \\
60 & 70.00 & 70.00 & 68.00 \\
70 & 60.00 & 61.25 & 60.00 \\
\hline
\end{tabular}

Table 5. Different temperatures were tried for the thawing of cryopreserved spermatozoa $\left(25^{\circ} \mathrm{C}\right.$ to $\left.60^{\circ} \mathrm{C}\right)$. Among the different temperature tried, higher motility was observed at the temperature of $40^{\circ} \mathrm{C}$ in Catla, Rohu and Mrigal. Post thaw motility was slightly lower in low and high temperatures. Post thaw motility of 80 to $85 \%$ was observed at the temperature of $40^{\circ} \mathrm{C}$.

Fertilization studies were conducted using cyopreserved milt from catla. Eggs collected from catla were used for the fertilization studies. This experiment was conducted in field condition. Cryopreserved milt from catla was mixed with eggs collected from catla and mixed together using feather.

\subsection{Cryoprotectant}

The results obtained in the present study revealed that the carp spermatozoa could be frozen by a simple method using insulated box and cryo can (without ant sophisticated freezing units like computarized freezing units) and the ways and means to improve their viability for longer periods were attempted for three species under tropical condition.

In this experiment modified Cortland medium was found to be a better extender than Cortland medium for grass carp [24] and Channel catfish [11]. Based on the reports available Modified Cortland medium is ideal for cryopreservation of carp spermatozoa. Modified Cortland medium is used as an extender in this study.

In general, glycerol was reported as the best cryoprotectant for mammalian and marine fish spermatozoa by Scott and Baynes [30]. Among the cryoprotectant (glycerol and DMSO) tested in the present study, 10 to $15 \%$ of glycerol and DMSO showed the maximum motility. Similar observation was made by Lakra [20] who reported glycerol as the best cryoprotectant for carp. In the present study, 10 to $15 \%$ of glycerol and DMSO equally performed well for the cryopreservation of carp spermatozoa

Piironen and Hyvarinen [27] reported glycerol as the best cryoprotectant for white fish (Coregonus muskun) and suggested that glycerol might play an important role in the metabolism of whitefish sperm. DMSO was found to be the best cryoprotectant for the spermatozoa of salmonids and other freshwater fishes [Ott and Horton, 1971b; 10]. Chen et al. [8] found that DMSO at $10-12 \%$ concentration resulted in better cryopreservation of carp spermatozoa. Gwo et al. [14] and Gwo [12] found that 20\% DMSO as better concentration for the freezing of spermatozoa of Atlantic croaker and black grouper respectively. Piironen and Hyvarinen [27] obtained better results with 20\% glycerol for whitefish. Moreover, they observed a higher concentration of glycerol in the seminal plasma of whitefish and attributed the need for higher concentration (20\%) of cryoprotectant (glycerol) to this fish.

\subsection{Equilibration Time}

Studies concerning equilibration time in the spermatozoa of tilapia revealed that providing no equilibration time resulted in best post-thaw fertility [15]. Similar findings were recorded in salmonids [25, 26, 35]. Billard [2] registered decreased post-thaw fertility in rainbow trout sperm equilibrated for $1 \mathrm{~min}$ and opted for freezing immediately after dilution. Chao et al. [5] noticed that the motility of black porgy sperm was maintained at the highest levels, when the equilibration time was within $10 \mathrm{~min}$. Chao et al. [6] recorded similar result with tilapia spermatozoa. Linhart et al. [22] recorded poor post-thaw sperm motility in 
common carp at 20 min of equilibration time than that frozen immediately.

Compare to all the above reports, in the present study, significant difference was noticed in the post-thaw motility, with reference to different equilibration period. Maximum post motility was observed in the equilibration time of 20-40 min. Moreover, $20 \mathrm{~min}$ equilibration time was sufficient to prepare the semen samples for freezing. Steyn et al. [32] also allowed equilibration time according to the period required to dilute and prepare the semen samples for freezing.

Stoss and Holtz [36] found that the DMSO concentrations between $10-20 \%$ provided higher post-thaw fertility (77\%) in rainbow trout when the equilibration time was kept at a minimum. Gwo et al. [13] equilibrated the spermatozoa of Atlantic croaker for $5 \mathrm{~min}$ and $60 \mathrm{~min}$ and in both the cases the fertility rate decreased with increasing concentration of the cryoprotectant.

\subsection{Thawing Rate}

If the freezing of spermatozoa is done at a quicker rate, the thawing should also be done at a rapid rate in order to prevent cell injury by water recrystallization [32]. In the present study, higher motility rates were observed, when the spermatozoa were thawed at a water temperature of $40^{\circ} \mathrm{C}$ and lower post-thaw motility in relatively higher temperature. In the present result indicated that, the slow thawing rate (especially air thawing) should be avoided. Mazur [23] also explained that, rapidly frozen cells would suffer when thawed at a slower rate. The present finding agreed with the following studies. Steyn et al. [32] found that thawing temperature of $25^{\circ} \mathrm{C}$ was superior to $7^{\circ} \mathrm{C}$ in the case of sharptooth catfish spermatozoa. Gwo et al. [14] obtained higher fertilization with frozen spermatozoa thawed at higher thawing temperature $\left(25-50^{\circ} \mathrm{C}\right)$ and the fertilization rate decreased at lower thawing temperature $\left(0^{\circ} \mathrm{C}\right)$. In contrast to the result obtained in the present study, Bolla et al. [4] found that slow thawing of Atlantic halibut sperm at $10^{\circ} \mathrm{C}$ gave best post-thaw motility.

Immediate use of the thawed sperm for fertilization has been recommended for different fishes. [21, 34, 16]. A delay of 30 seconds resulted in a significant drop of $15 \%$ in the fertilization rate in rainbow trout, while a delay of $5 \mathrm{~min}$ after thawing, dropped the fertilization rate to as low as $10.5 \%$ [34]. When the sperm samples of common carp, mrigal and rohu were observed under a microscope 2-3 min after thawing, a reduction in motility was observed. Therefore, it is evident that the carp sperm should be used for fertilization immediately after thawing to get best results.

\subsection{Fertility Studies}

The cryopreservation technique has been improved in such a way that the fertilization rate obtained with the cryopreserved spermatozoa was found to be equal or even higher that with fresh spermatozoa $[9,7]$. But in many cases, the fertilization rate was found to be lesser than that of fresh spermatozoa $[37,14,28]$. In the present study also, the fertilization rate with cryopreserved sperm was found to be lower than that, with fresh sperm in all the three species (Catla, rohu and mrigal). Piironen [28] also observed similar result with the spermatozoa of Arctic charr and he explained that the procedures adopted were sub optimal and provided only partial protection to the sperm cell.

\section{Conclusion}

In the cryopreservation of fish spermatozoa, motility has been considered as a key parameter for assessing the viability of sperm cells [37, 22]. Lahnsteiner et al. [19] observed that the motility rate of cryopreserved sperm after thawing approximately correlated with the fertilization rate. Salisbury et al. (1978) found that the motility served as a measure of flagella movement and did not guarantee fertility. Gwo [12] observed that the morphology of about $90 \%$ of the sperm heads of black grouper were intact after freezing and thawing and he reported that sperm motility should be a relatively reliable indicator of its ability to fertilize eggs. The present findings thus agree with the views of Gwo [12] in this regard.

Chao et al. [6] also faced a problem of reduction in the fertility rate with fresh and frozen spermatozoa of tilapia. They suggested that the motility could be the best criterion for evaluating the success of sperm preservation. With repeated trials and improvement through feed back, they achieved a maximum fertilization rate of $75.5 \%$ with the frozen-thawed spermatozoa samples having a post-thaw motility of $80 \%$. This gives a valid indication that the rate of fertilization with cryopreserved sperm could be improved through repeated trials.

\section{Acknowledgement}

We thank the Dean, Fisheries College and Research Institute, Tuticorin-8, Tamilnadu, India for his constant 
support, and suggestions in successful completion of this research work.

\section{References}

1. Baynes S M, and Scott A P (1987). Cryopreservation of rainbow trout spermatozoa: The influence of sperm quality, egg quality and extender composition on post-thaw fertility, Aquaculture, vol 66, 53-67.

2. Billard R (1980). Prolongation de la duree de motilite et du pouvoir fecondant des spermatozoids de Truite arcen-ciel par addition de thephylline au milieu de dilution, C. R. Academic Science, Paris, vol 291, D, 649-652.

3. Blaxter J H S (1953). Sperm storage and cross-fertilization of spring and autumn spawning herring, Nature (London), vol 172(4391), 1189-1190.

4. Bolla S, Holmefjord I et al. (1987). Cryogenic preservation of Atlantic halibut sperm. Aquaculture, vol 65(3-4), 371-374.

5. Chao N H, Chao W C et al. (1986). The biological properties of black porgy (Acanthopagrus schlegeli) sperm and its cryopreservation, Proceedings of National Science Council, B. Taiwan, vol 10(2), 145-149.

6. Chao N H, Chao W C et al. (1987). The properties of tilapia sperm and its cryopreservation, Journal of Fish Biology, vol 30(2), 107-119.

7. Chao N H, Tsai H P, and Liao I C (1992) Short and Long-term cryopreservation of sperm and sperm suspension of the grouper, Epinephelus malabaricus (Bloch and Schnaider), Asian Fisheries Science, vol 5, 103-116.

8. Chen S L, Liu X T et al. (1992). Cryopreservation of spermatozoa of silver carp, common carp, blunt snout bream and grass carp, Acta Zoologica sínica, vol 38, 413-424.

9. Cognie F, Billard R et al. (1989). La cryopreservation de la laitance de la carpe, Cyprinus carpio, Journal of Applied Ichthyology, vol 5(4), 165-176.

10. Erdahl D A, and Graham E F (1978). Cryopreservation of salmonid spermatozoa, Cryobiology, vol 15, 362-364.

11. Guest W C, Avault J W Jr et al. (1976). Preservation of channel catfish sperm, Transaction American, Fisheries Society, vol 105, 469-474.

12. Gwo J C (1993). Cryopreservation of black grouper (Epinephelus malabaricus) spermatozoa, Theriogenology, vol 39(6), 1331-1342.

13. Gwo J C, Kurokura H et al. (1993). Cryopreservation of spermatozoa from rainbow trout, common carp and marine puffer, Bulletin of Japan Social Science Fish, vol 59(5), 777-782.

14. Gwo J C, Strawn K et al. (1991). Cryopreservation of Atlantic croaker spermatozoa, Aquaculture, vol 94(4), 355-375.

15. Harvey B (1983). Cryopreservation of Sarotherodon mossambicus spermatozoa, Aquaculture, vol 32, 313-320.
16. Harvey B, Kelley R N et al. (1982). Cryopreservation of Zebra fish spermatozoa using methanol, Canadian Journal of Zoology, vol 60(8), 1867-1870.

17. Edwin M J, and Ulaganathan V (1988). Deep freezing of semen, Tamil Nadu Agriculture University, Coimbatore, vol 46.

18. Kumar K (1989). Studies on cryogenic preservation of carp spermatozoa, Das P, Jhingran A G (Ed), Fish Genetics in India, Today and Tomorrow's Printers and Publishers, New Delhi, 199-206.

19. Lahnsteiner F, Wiesmann $\mathrm{T}$ et al. (1992). Fine structural changes in spermatozoa of the grayling, Thymallus thymallus (Pisces: Teleostei), during routine cryopreservation. Aquaculture, vol 103(1), 73-84.

20. Lakra W S, (1992). Fish gamete and embryo cryopreservation research in India, Billard R (Ed.), Workshop of Gamete and embryo storage and cryopreservation in Aquatic organisms, France, 16.

21. Legendre M, and Billard R (1980). Cryopreservation of rainbow trout sperm by deep-freezing, Reproduction, Nutrition, Development, vol 20, No 6, 1859-1868.

22. Linhart O, Liehman P et al. (1992). Long term preservation of common carp (Cyprinus carpio L) spermatozoa, Billard $\mathrm{R}$ (Ed.), Workshop on gamete and embryo storage and cryopreservation in aquatic organisms, France, 40.

23. Mazur P (1977), The role of intracellular freezing in the death of cells cooled at supraoptimal rates, Cryobiology, vol 14, 251-272.

24. Moczarski M (1976). Cryobiological factors in grass carp sperm preservation, 8th Proceeding International Congress Animal Reproduction, 1030-1033.

25. Ott A G, and Horton H F (1971a). Fertilization of Chinook and coho salmon eggs with cryopreserved sperm, Journal of Fish Research Canada, vol 28(5), 745-748.

26. Ott A G, and Horton H F (1971b). Fertilization of steel head trout (Salmo gairdneri) eggs with cryopreserved sperm, Journal of Fish Research Board Canada, vol 28(12), 1915-1918.

27. Piironen J, and Hyvarinen H (1983). Cryopreservation of spermatozoa of the whitefish, Coregonus muskun pallas, Journal of Fish Biology, vol 22(2), 159-163.

28. Piironen J (1993). Cryopreservation of sperm from brown trout (Salmo trutta lacustris L.) and Arctic charr (Salvelinus alpines L.), Aquaculture, vol 116 (2-3), 275-285.

29. Polge C, Smith A U et al. (1949). Revival of spermatozoa after vitrification and dehydration at low temperature, Nature, vol 164, 666-666.

30. Scott A P, and Baynes S M (1980). A review of the biology handling and storage of salmonid spermatozoa, Journal of Fish Biology, vol 17, 707-739.

31. Snedecor G W, and Cochran W G (1976). Statistical methods, Oxford and IBH publishing Co, 593. 
32. Steyn G J, Van vuren J H J et al. (1985). Preliminary investigations on the cryopreservation of Clarias gariepinus (Clariidae : Pisces) sperm, Water, S.A, vol 11(1), 15-18.

33. Stoss J, and Donaldson E M (1982). Preservation of fish gametes. Richter C J J and Goos H J T (Eds.), Preccedings of International symposium on reproducyive physiology of fish, Wageningen, The Netherlands, 114-122.

34. Stoss J, and Holtz W (1981a). Cryopreservation of rainbow trout (Salmo gairdneri) sperm, I. Effects of thawing solution, sperm density and interval between thawing and insemination, Aquaculture, vol 22, 97-104.

35. Stoss J, and Holtz W (1983a). Cryopreservation of rainbow trout (Salmon Gairdneri) sperm, III Effect of proteins in the diluent, sperm from different males and internal between sperm collection and freezing, Aquaculture, vol 31, 275-282.

36. Stoss J, and Holtz W (1983b). Cryopreservation of rainbow trout (Salmo gairdneri) sperm, IV. The effect of DMSO concentration and equilibration time on sperm survival, sucrose and $\mathrm{KCl}$ as extender components and the osmolality of the thawing solution, Aquaculture, vol 32(3-4), 321-330.

37. Stoss J (1983). Fish gamete preservation and spermatozoan physiology, Hoar W S, Randall D J, and Donaldson E M (Eds.), Fish Physiology, Academic Press, New York, vol IX B, 305-350.

38. Terner C (1986). Evaluation of salmonid sperm motility for cryopreservation, The Progressive Fish-Culturist, vol 48(3), 230-232. 